\title{
Young Carers Research, Practice and Policy: An Overview and Critical Perspective on Possible Future Directions
}

\author{
Stephen Joseph ${ }^{1}$ (I) $\cdot$ Joe Sempik ${ }^{2} \cdot$ Agnes Leu $^{3} \cdot$ Saul Becker $^{4}$
}

Received: 15 March 2019 / Accepted: 8 May 2019 / Published online: 20 May 2019

(c) The Author(s) 2019

\begin{abstract}
Many children, adolescents, teenagers, and young adults have caring responsibilities for parents and family members. These young carers and young adult carers are present in every country. Their responsibilities include domestic chores as well as intimate personal care and other forms of helping which are generally seen as the responsibility of adult professionals. First, this article provides an overview and critical perspective on young carers research. Research suggests that $2-8 \%$ of children and young people are carers and that the caring role has an impact on their education, health, wellbeing, social opportunities and employment prospects. Various countries have responded differently with regards to policy: some have well developed services and recognition in law whilst others are only just beginning to recognise the problem. Second, we discuss the issues and challenges for research and propose a new agenda for the development of policy, research rigour, more theoretical sophistication, and a greater awareness of the need for interdisciplinary and multiagency working. Furthermore, we call for participatory and action led research that can provide greater insights into the lived experiences of young people, their needs and how these can be met.
\end{abstract}

Keywords Young carers $\cdot$ Prevalence $\cdot$ Research $\cdot$ Theory $\cdot$ Policy $\cdot$ Interdisciplinary

\section{Introduction}

It is over 25 years since Aldridge and Becker (1993) first identified the role that some children, adolescents, and teenagers under 18 years in the United Kingdom (UK) have as caregivers for family members. The term "young carers" is now widely used in scholarly literature and in public policy to describe children and young people who provide regular

Stephen Joseph

Stephen.joseph@nottingham.ac.uk

Joe Sempik

joe@sempik.com

Agnes Leu

Agnes.Leu@Careum.ch

Saul Becker

Saul.becker@sussex.ac.uk

1 School of Education, University of Nottingham, Nottingham NG8 1BB, UK

2 University of Nottingham, Nottingham, England, UK

3 University of Zurich, Zurich, Switzerland

4 University of Sussex, Sussex, England, UK and substantial care to ill or disabled family members. The term "young adult carers" was later introduced by Becker and Becker (2008) to describe those young adults aged between 18 and 24 years who provide care. The reasons for providing care are complex and often related to the absence of other informally available networks, the lack of suitable formal care arrangements, as well as love and natural family bonds to the person in need. Becker (2007) described the caring continuum as ranging from caring about the person to caring for the person. Caring about reflects the usual activities conducted by most young people, for example, helping with cleaning and tidying and carrying out basic domestic chores. In cases where there are difficulties, disability or illness within the family, the young person may increase their level of care by spending more time carrying out domestic chores and taking on intimate, specialized and medical care; their position on the continuum gradually changes from "caring about" to "caring for". With that comes a heavier burden of commitment and responsibility; their time and attention are taken up with the caring role. Much research has accumulated over 25 years but there remain important gaps. The aim of this article is to highlight those gaps and set the research agenda for the next 25 years. Following an 
overview of the research and public policy literature identifying the major challenges and issues facing the field we will discuss the new directions that we think research in this field must now take.

\section{Prevalence and Effects of Caring}

Recognised as an invisible, hidden, and a vulnerable workforce (Stamatopoulos 2015), children and young people with a high level of caring responsibilities have been shown to exist across European countries (e.g. Norway, Sweden, Austria), the United States, Canada, Australia and New Zealand, Sub-Saharan Africa and the Middle East (see Leu and Becker 2017a). Whilst there is some variation in estimates of prevalence, figures suggest that between 2 and $8 \%$ of all children, young people, and young adults in advanced industrialized capitalist societies are carers, depending on the methodology which is used to identify and count them (see Leu and Becker 2019). It is impossible to be more precise than this as the definition of caring, methodology and sampling, are not consistent, and even in the most sophisticated studies truly representative and sufficiently large samples have rarely been obtained. Also, figures are not static but vary over time, by geography of the country, and ethnicity and other demographic factors (Wayman et al. 2016).

Prevalence studies have provided data for developed countries. Until relatively recently data were limited for Africa and Asia; however, a number of researchers have now explored the roles of young carers in these countries and the context in which they enact those caring responsibilities. For example, Robson et al. (2006) showed that, in the midst of the HIV/AIDS epidemic in Lesotho, Tanzania and Zimbabwe, many children and young people had the responsibility of looking after their dying parents in addition to carrying out the domestic chores and work that would normally be conducted by their parents. The prevalence of caring may be higher in African countries than the $8 \%$ because of the extent of familial AIDS-illness (Cluver et al. 2012), but as yet sufficiently detailed studies have not been conducted.

In general, however, research shows that young carers and young adult carers in different countries carry out the same range of caring activities (Nagl-Cupal et al. 2015). One useful comparison is between young carers in the UK and those in Tanzania (taken from a study of young carers in these countries who care for parents with HIV and AIDS) (Evans and Becker 2009). All of the children in both countries carried out household chores, and almost half of them ( $45 \%$ in each country) provided some form of personal (intimate) care. The majority of children in both countries ( $82 \%$ and $64 \%$ respectively) were also involved in providing healthcare for their parents or families and some also cared for their siblings. While there are similarities, two areas of difference were also observed. Only $9 \%$ of young carers in the UK contributed to the household income, however, in Tanzania, almost half of the children were engaged in some form of income generation such as begging or casual work. Many young carers in Tanzania, therefore, have to provide an income for the household in addition to the caring tasks they have to do. The lack of a state provided welfare system and income protection scheme severely exacerbates the financial difficulties of those families in parts of Africa and other poorer countries-hence, as the parents are unable to earn a wage, they have to rely on their children as providers of income in addition to their roles as carers.

Overall, research shows that the role of young carers is similar regardless of the country or continent but that the detail of that role will be affected by local considerations or circumstances. Having identified that a substantial minority of young people are engaged in caring roles, a major focus of research has been to understand the impact of caring on the young people's, health, wellbeing, education and social and economic life chances.

First, young people who care for individuals may carry out the same tasks as paid and trained health and social care practitioners. But they are unpaid and untrained. They are exposed to numerous risks, and their lack of knowledge about the medical diagnosis and lack of training contribute to those risks (Leu and Becker 2017b). For example, Cluver et al. (2013) showed that children in sub-Saharan Africa who look after parents with AIDS are at greater risk themselves of pulmonary tuberculosis. Second, a wide range of qualitative studies have shown that young carers and young adult carers may experience various economic and social disadvantages and difficulties, including restricted educational opportunities and employment (e.g., Kaiser and Schulze 2015), difficulties in meeting the demands on them in university education (e.g., Kettell 2018), reduced social capital (e.g., Barry 2011), and experience of stigma leading to secrecy and social withdrawal (e.g., Bolas et al. 2007). Metzing-Blau and Schnepp (2008) found that families turn to secrecy as a means to keep the family together as it is felt to be under threat, thus the disadvantages can become compounded. Family relations can also be strained (e.g., Stamatopoulos 2018). Third, there are found to be problems with health and well-being. At school, young carers may experience bullying (e.g., Moore et al. 2009), experience physical injury from lifting (e.g., Fives et al. 2013), experience difficulties in health and well-being (e.g., Hamilton and Adamson 2013), and in some contexts having to go hungry (e.g., Cluver et al. 2012). Fourth, the provision of intimate care transgresses the accepted social norms regarding the relationship between a young person and his or her parent 
and this may affect their development, social integration, or interaction with their peers. Rose and Cohen (2010) in their meta-synthesis of qualitative research with young people themselves offers a different way of understanding how being a young carer is experienced as an process of identity formation, and that it might therefore be difficult to separate them from this role. Fifth, not all studies show only adverse effects. For example, Svanberg et al. (2010) in their study of children caring for a parent with dementia also emphasised their resilience and that only few showed depressive symptoms. Indeed, much of the above research largely adopts a medicalised approach to understanding the impact of caring as if it were a pathogen that leads to illness, but studies have also shown that caring may be associated with increasing maturity (e.g., Fives et al. 2013), can lead to positive changes (e.g., Joseph et al. 2009a), closer relationships with parents and the feeling of being well prepared for life (e.g., Hunt et al. 2005), and the ability to foster qualities of compassion and empathy (e.g., Stamatopoulos 2018). Finally, young carers may feel invisible and unacknowledged as caregivers (e.g., Bjorgvinsdottir and Halldorsdottir 2013).

Stamatopoulos (2018) in her qualitative focus group study with young carers from both the Greater Toronto area and the Niagara Region of Southern Ontario referred to the "young carer penalty", to describe how young people who care are disadvantaged, and restricted in their opportunities; those from single-parent and single-child families, and dealing with more stigmatised and debilitating problems had the highest penalty. Other qualitative research has interviewed professionals about their perspective on young carers, emphasizing that they are seen as an invisible, hidden, and vulnerable workforce, that is isolated, stigmatized, suffering from restrictions in education, leisure, and employment (Gray et al. 2008). Overall, qualitative research has been very rich in the detail and breadth of the difficulties it has described young people as experiencing. However, it has tended to consist of small scale studies of selected groups of young carers. As such, it is uncertain to what extent findings can be generalized.

When larger scale surveys have been conducted of young carers, a substantial minority are found to have disadvantages and difficulties. In a survey of young adult carers in the UK, for example, Sempik and Becker (2013) found that those still at school were absent for around $5 \%$ of their days and reported that caring interfered with approximately a quarter of all of their school days. In other contexts, however, the rate of absenteeism may be much higher. Stamatopoulos (2018) in her study of Canadian young carers found a specific absenteeism rate of $10.8 \%$. In another study, Sempik and Becker (2014a) found that $56 \%$ of young adult carers at college or university reported that they were experiencing difficulties with their studies because of their caring and some feared dropping out.
In an Australian study, Moore et al. (2006) showed that young carers appreciated school but care responsibility along with a lack of services, family or social issues such as poverty and isolation led to absences and educational failure. Evans' and Becker's (2009) study highlighted the anxiety felt by young carers both in Tanzania and the UK. In both countries, the young people feared for the future, for example, they worried about what would happen when the person they were caring for died.

Cree (2003) showed that whilst a sample of 61 young carers from Scotland had many of the worries that are associated with adolescence, such as about their appearance, they also had worries and problems that arose from their caring roles. Almost two thirds reported that they had difficulty sleeping and almost a third reported difficulties in eating. A similar number said that they had self-harmed and had suicidal thoughts. Whilst the survey did not measure specific diagnosable mental health problems, it suggests that those children were in danger of developing such problems in the future, if such problems were not present already. In their survey of young adult carers, Sempik and Becker (2013) reported that $38 \%$ of those still at school said they had some form of mental health problem: for those at college or university, the figure was 45\% (Sempik and Becker 2014a), whilst for those who had left education and were in work or were unemployed, the figure was 51\% (Sempik and Becker 2014b). Lloyd (2013) conducted a survey of 4192 children in Northern Ireland, identifying $12 \%$ who said they helped looked after someone in their household. Those children scored lower on measures of health and well-being, reported that they were bullied more frequently and had poorer educational aspirations.

While these studies move beyond the small scale qualitative studies in providing results with larger samples, and thus more useful estimates of the scale of the problems for developing policy, the samples are often selected from carers associations and thus cannot be said to be truly representative of all young people who care. Studies have reported that recruitment can be difficult, with for example, response rates from schools or health professionals being low (e.g., Thomas et al. 2003).

But even in showing that a substantial percentage of young people report difficulties it is not certain that these can actually be attributed to caring. Illness and injury in the family are often stressful experiences for young people regardless of their caring role (Joseph et al. 2000). Other studies have tested for statistical association between the extent of caring and problems. Such studies are rare and show mixed findings, with some reporting that greater caring activity is associated with psychological problems (i.e., Joseph et al. 2009a; Nagl-Cupal et al. 2014) but not in others (i.e., Kavanaugh 2014; Becker and Sempik 2018; Leu et al. 2019). Correlation does not however imply causality 
and as yet there are no prospective studies showing a clear relationship between caring and subsequent problems that would lend support to the hypothesis that they are causally related. Kavanaugh et al. (2016) note that there is a need for much larger scale, longitudinal studies.

It seems unlikely, however, that caring has no adverse effect, but as the extent of the problems are unclear and it cannot be assumed that all children and young people who care are actually adversely affected, we have to conclude that there are fundamental gaps in the scientific knowledge yet to be addressed. There is a need for research to untangle how caring is helpful to the development of a young person and in what circumstances it can be detrimental.

\section{Developments in Policy}

Young carers and young adult carers carry out roles at home that in the general workplace (care homes, hospitals and other similar institutions) would usually be performed by trained and qualified adults (who may also have specific qualifications for those roles). These roles which are usually assumed by adults involve a high level of capability and responsibility and may also involve a high level of specialist skill and knowledge. Additionally, young carers often work long hours in their caring role (often longer than standard employment) and are not paid; and by not being paid they save a substantial amount of money for health and social care services (Leu and Becker 2017b). Due to their relationship with those being cared for, unlike employees, they are not free to leave their work and are tied into their caring role until their circumstances change (which can be much later in their adulthood). Additionally, unlike most paid employment, the hours and times that the young carers are required to work can be unpredictable leading to stress and anxiety. Hence, their ability to develop, and their opportunities for education and employment can be severely curtailed; a point also discussed by Stamatopoulos (2018) who discusses how the older carers in her study were more distressed because their grades and lack of extracurricular activities now directly affected their postsecondary applications. For professionals conducting such work as part of their paid employment they will have received training; be registered with and covered by various professional codes of conduct; able to draw on the support of their agency and organization in case of difficulties; have colleagues who can offer support; and have insurance to cover any mishaps for which they are deemed as responsible.

In terms of policy, it is reasonable to expect that support for young people in their role should be similarly provided. However, young carers rarely, if ever, receive training for caring roles. This must be addressed. However, even when some form of training is made available, it may not be welcome by a young carer as they may want to keep their role a secret, feeling it to be an embarrassment, possibly out of fear of shaming their parent, or the consequences of disclosure and the fear of child removal (e.g., Moore and McArthur 2007). Thus, while it might seem self-evident that some form of training and support for young people who have a caring role would often be helpful, and we believe should be available, this is actually a controversial position insofar as it suggests that it is acceptable that young people provide such care in the first place. On the one hand, it is important that young people are active agents of their own lives, but on the other this is not to suggest that the state does not have a responsibility to provide the support needed by families. In making such support available, policy development must consider carefully issues of confidentiality, privacy, and choice.

Better, however, that such support was not needed in the first place. Our position is that the first aim of policy towards this issue should always be to provide support for families such that young people do not have to take on roles that are disruptive to their own development, functioning, and education. However, as the research shows, the issue of young carers and young adult carers is complex, and even if this were fully implemented as a policy some level of caring would continue to exist. Different countries have reacted with different levels of response in terms of recognition in law, policy change, and practical support. Their response has been influenced by a range of different factors.

Becker (2007) first compared the responses of UK, Australia, the US and Sub-Saharan Africa to the issue of young carers in order to develop a country-specific classification. This has been developed further by Leu and Becker (2017a) who propose that country-specific research and the presence of lobbying or championing organizations are important drivers in affecting policy change. Country-specific research is able to show conclusively that young carers do exist in that country and what their needs are, therefore not relying on extrapolation of findings from other countries (Leu et al. 2016a, b). Such local data are important in influencing politicians and policy-makers as the demonstration of such a child welfare issue then requires a response from them. In other words, what might have continued as a hidden 'private' issue has become the focus for public policy and intervention.

Leu and Becker (2017a) have analysed the extent of awareness and policy responses internationally and have proposed a model with seven levels of response. The response levels are based on a number of characteristics which demonstrate the presence or absence of specific legal rights or entitlements for young carers, or other rights that could be utilized on their behalf, for example, as "children as next of kin" in Sweden (Health Services Act 2010). These characteristics include whether children have rights to receive 
an assessment of needs as young carers. Such rights do not necessarily need to be legal rights, but if they are not legal rights how strong are they, and are they enforceable? Do the countries have specific welfare or social policies that refer to young carers? Do codes of practice for health and social care professionals specifically refer to young carers as a distinct group, and are they recognised as such by the professions? Is there a level of awareness of the issue of young carers amongst the general population and among health and social care professionals? Are there projects or interventions specifically for young carers? Or specific therapeutic interventions for them? As mentioned above, country-specific local research and an active research presence in the country are also active drivers of policy responses, as is the presence of supporting organisations.

Using these key characteristics, Leu and Becker (2017a, p. 752) have classified countries according to their level of awareness of the issue of young carers and their policy response. The highest level (Level 1) which they have termed "Incorporated/sustainable" describes a response where there is "extensive awareness at all levels of government and society of the experiences and needs of young carers; sustained and sustainable policies and interventions aimed at meeting young carers' needs and promoting their health, well-being and development" and "responses and law built on a foundation of reliable research evidence and clear legal rights". They could find no countries that could be placed within that level which is essentially the standard that countries should seek to attain.

The UK (on its own) was classed as "Level 2" (Advanced) where there was "widespread awareness and recognition of young carers amongst public, policy makers and professionals" and "specific legal rights" among other characteristics. The latter referring to changes in UK law (the Children and Families Act 2014; and the Care Act 2014) which includes specific protection for young carers and support for them. Such changes came about because of research produced in the UK which showed the local situation in detail, and because of the activities of non-governmental organisations and the researchers themselves. They campaigned for policy change and used the published research to raise awareness of the issue among policy-makers. Prior to specific legal protection, the UK had also published in 2008 a National Carers Strategy (since "refreshed") which set an agenda that by 2018 children would be protected from inappropriate caring; would have the support they need to be able to learn; be able to develop and thrive so as to enjoy a positive childhood; and to achieve against government-set outcome targets.

Australia, Norway and Sweden were classed as "Level 3" (Intermediate; i.e., "some awareness") and Austria, Germany and New Zealand as "Level 4" (Preliminary; i.e., "little public or specialist awareness"). Six countries and one region (i.e., the US, The Netherlands, Switzerland, Italy,
Ireland, Belgium, and Sub-Saharan Africa) were classified as "Level 5" (Emerging; i.e., "Growing public or specialist awareness") and four (i.e., France, United Arab Emirates, Finland, and Greece) as "Level 6" (Awakening; i.e., "Embryonic awareness"). All other countries where there was no evidence of research or policy response were classified as "Level 7" with "No apparent awareness".

Hence, internationally, there is a wide range of responses to the issue of young carers. The extent of research conducted nationally has an important bearing on the policy response. Generally speaking, countries which have carried out more research were seen as at a higher level in Leu and Becker's framework than others, but their characterization was not based on the quantity of research but on their estimation of that country's awareness in policy. As a result countries such as Norway and Sweden which have relatively less research activity received a higher classification than some other countries which have greater research activity but still less policy awareness.

Leu and Becker's (2017a) classification system is not fixed but was developed to create awareness and dialogue between social scientists and policy makers internationally, which it has succeeded in doing. New research is emerging all the time; some countries that were lower in the classification are likely to emerge much higher at the next iteration. Although Canada and the United States have been lagging behind in recognizing and supporting young carers, research interest in Canada (e.g., Stamatopoulos 2016) and the United States (e.g., Kavanaugh et al. 2016) is building rapidly, and we might expect to see new developments in policies and community support to follow. It appears, therefore, that policy-makers may benefit from access to local research that shows the status in their own countries, but for those policy makers who already have an awareness of the issues, a lack of research may not impede them in acting to define policy. This may be to take action in response to local and national situations. As much as we, as social scientists, value research data to guide policy and practice we recognize that it is only one road to policy; activism to bring about change is also important in developing policy, and certain types of research may be more attractive to policy makers than others.

Countries have also responded to the growing international research base on young carers by commissioning their own national research. Switzerland, currently at Level 5, is a case in point (Leu et al. 2016a, b). Researchers in Switzerland have recently completed a number of studies that have estimated the prevalence of young carers and explored awareness of the issues among health and social care professionals (Leu et al. 2019); and in ongoing research they are continuing to explore the experiences of children and young people with caring responsibilities. By conducting national research, the aim is to drive policy changes to improve support for young carers and young adult carers. This is much 
needed as studies in several countries have shown that the level of practical support received from healthcare and home-help professionals do not meet the needs of young carers and those they care for (Moore and McArthur 2007). In many families in the UK and internationally, the caring roles of children and young people are hidden and remain a "private" family matter rather than an issue for public policy intervention.

It is clear that we think that increasing awareness is important, but it is not without its problems. The terms "young carer" and "young adult carer" are controversial. Parents may feel that they are cast in positions of dependence or inadequacy, and left feeling pathologized and that they are a threat to their children (Newman 2002). There is likely at least some truth to this, but to what extent such an observation generalizes to the wider population is uncertain. On the other hand, the benefit of the introduction of these terms and dedicated research interest is that it has led to massive deployment of agencies and services which seems to be valued by young people. Young carers themselves may find solace in the label and value being identified and acknowledged. As such, there are strong arguments for the use of the terms. Similar arguments are often put forward for other labels and diagnoses that people find helpful in understanding themselves and in accessing services, but, as social scientists we need to be much more wary ourselves of the validity of the terms we use. It is one of the dangers of research in this field that it may lead young people to begin to think of themselves differently and potentially negatively. The field has not been without its critics, such as Olsen (2000), who has called for greater sociological understanding of how the term "young carer" is a social construction that potentially problematises childhood.

As discussed above, research into young carers has developed substantially over the past 25 years, overcoming many of the methodological problems raised at the inception of the field (Olsen 1996). The field has moved from a flimsy evidence base to one that more substantially supports the development of policy; however, much remains to be done to build upon these foundations, and to develop more nuanced understandings of caring and its impacts. Increasingly, it is recognised that the extent and nature of caring differs geographically across and within countries such that the target population is not a homogenous one, where a 'one size fits all' policy is appropriate (see, Hill et al. 2009).

\section{Directions for Theory, Research, Practice and Policy}

In this section, we will consider the challenges and issues and the ways forward for research in six areas: definitional issues that set the agenda, the international focus, research quality, theoretical sophistication, participatory research, and the need for multiagency and interdisciplinary working and awareness.

\section{Definitional Issues That Set the Agenda for Research}

One of the problems noted by researchers has been that there is no single definition of a young carer (e.g., Aldridge 2018). Without a universal definition it is difficult to assess prevalence of young carers and young adult carers consistently across studies. As such, estimates of populations of young carers are at variance with each other. Some use census information which is based on reporting by adults in the household. Others use self-identification methods by young people themselves. This is a problem insofar as researchers have seen a need to develop estimates of prevalence that are comparable across countries. Policy makers will be interested in knowing the extent of a problem and this drives researchers to develop such research. The difficulty of developing a clear definition is widely acknowledged by researchers as caring is a highly subjective and variable experience. We suggest, however, that the difficulty in definition is that caring is not one thing, and that once we disentangle it into its components it is possible to develop a clearer and more useful set of definitions. Below, we will provide what we think is a more nuanced conceptualization.

As already noted, "young carers" and "young adult carers" are social constructions, helpful in one way for drawing attention to an issue faced by many children and young people, but unhelpful in other ways if they reify the idea that this really is a single population of young people, all with the same issues, who are all adversely affected by their experiences in the same way. It is understandable that policy makers want to know what percentage of children and young people are carers but caring is on a continuum and is not a dichotomous experience in which the person is either a carer or not a carer. Also, there are different dimensions to care, for example, the extent of caring (i.e. time spent caring) and the type of care carried out, for example, household tasks or personal care. Striving to produce such an understanding tends to lead to percentages that are either over inclusive of all children who have some caring role or exclusive to those at the more extreme end of caring responsibilities.

We have had personal experience of this in our own recent research in which we conducted a representative survey of 925 young carers in England (Joseph et al. 2019). Our approach to this was in two stages. First, we ascertained the percentage of children who provide some help, no matter how minimal, to someone in their home who was ill or disabled. We found that this was around $20 \%$ of all young people; these could, therefore, be classified as young carers in the very broadest sense. Second, using a standardized assessment tool that asks about caring responsibilities-a 
revised survey version of the Multidimensional Assessment of Caring Activities (MACA-YC18) -we ascertained the amount of caring that the young person did. We found that around $32 \%$ of the young carers were carrying out a "at least a high amount of caring" as defined by the assessment tool (7\% of the total sample of all the young people), and $9 \%$ of young carers were classified as doing a "very high amount" of caring ( $3 \%$ of all young people). It is this latter smaller group that we would expect are most likely to experience difficulties and be adversely impacted by being carers, but it was the first figure of $20 \%$ of all young people that attracted the media attention and that of the various agencies concerned with promoting the welfare of young carers. All of the figures, 20, 7, and 3\%, are correct, but it is only through understanding how they each represent different populations that more nuanced policy can be developed.

Becker's (2000) definition that young carers are those that carry out, often on a regular basis, significant or substantial caring tasks and assume a level of responsibility which would usually be associated with an adults is often used. This is a broad definition, one which has come under criticism in recent years for a number of reasons; most notably that it excludes the impact of caring (Aldridge 2018). While we agree that bringing the focus on the impact of caring into the definition of what it is to be a young carer adds to the policy relevance, we would argue that this is too exclusive a definition. And, of course, children who provide care can still be categorized as "young carers" even in situations where there are few negative (or positive) impacts. One definition is too broad whereas the other we would argue is too narrow. But more importantly, it changes the focus of policy interventions to help with the burden of care to reducing the impact of caring on the carer. Policy needs to be able to address all aspects of caring.

As such, we think scientific enquiry should define caring in the broadest sense to be most inclusive in the first instance of all children who take on some caring role, and to understand the graduations of care along the continuum. We propose that caring can be best conceptualised as three concentric circles. The largest is young people who care about, i.e., those who are helping a relative in at least some minimal way with household activities but not to a greater extent than many of their peers who are not carers. The next is young people who care for, i.e., those who have taken on a level of responsibility that involves household activities but also more specialist and medical roles, but not to an extent that it interferes excessively with their social and educational activity. Finally, young people who themselves need care, i.e., those who have taken on caring activities well beyond the level of their peers who are not carers, involving specialized and medical activities, emotional work, and which prevents the young person engaging in the social and educational activities of his or her peers. Each group has its own distinctive needs. Recognizing this, policy targets can be more nuanced and responsive to the needs in families. In terms of policy and service goals, the implication would be to focus on prevention, assistance, and mitigation, respectively, as discussed by Purcal et al. (2012) in their analytical framework.

First, disabled and ill family members need to be provided with support such that children and young people are not required to provide care. This must always be recognised as a priority even if meeting such targets in full is unrealistic. Second, even if such support were available, because of family bonds and the wish to help, young people will always continue to provide care and they need support themselves to carry out their caring tasks. Resources need to be provided to young people to help them carry out their caring tasks. Finally, there is a need to be able to identify those children and young people under the most burden who are adversely affected and in urgent need of help not to support their caring activities but to support them and their mental health, education, and other ways in which they are impacted. Most often this will be to help with educational and psychological difficulties, but in some contexts there may be physical risks. This more nuanced definition goes some way toward avoiding problematizing the childhood of all young people who care.

Qualitative research with young carers themselves shows that they themselves feel that the best way that services can support them is to better support their cared for relatives (Moore and McArthur 2007). When asked about their own needs, young carers ask for assistance to participate in community life, to attend school, and to have opportunities to take a break from their caring responsibilities (Moore and McArthur 2007). These are intertwined policy objectives that need to be addressed simultaneously; research designed more explicitly to shape the policy agenda in all three ways rather than being responsive to a more simple notion of caring as a simple dichotomy.

As research moves forward, we must recognise the subtle graduations of caring and that no single definition is adequate. The terms young carer and young adult carer are broad descriptors only, as this is not one single population. We think our concentric circles model is a useful conceptual tool that encompasses different definitions and has clear policy implications.

\section{Developing the International Policy Focus}

Young carers are a global phenomenon and slowly, one by one, countries are beginning to respond to the challenges they face. There is a need to promote research to support and develop locally-based research and international comparisons. However, related to our discussion above, caring is a social construction that is understood in relation only 
to expectations of what are appropriate duties for a child or young person to take on. It is clear that we are coming from a frame of reference were it is seen as inappropriate for young people to take on unpaid roles of caring that are associated with trained professionals, but these expectations of normality vary from country to country. Thus, a single universal definition that allows meaningful comparisons across cultures is not possible, in the sense that in one culture a young person could be classified as a carer but not in another. Research which attempts such comparisons must be wary of cultural colonization and exporting the expectations of one culture to another. In this respect, Robson (2004) in writing about the child carers in Zimbabwe states that there needs to be less emphasis on the ideas of childhood as a time of play and innocence and more emphasis on defending their rights to work and be supported in their work.

Young carers do not always self-identify as such, often viewing what they do as part of a normal familial relationship with bonds of reciprocity and love (Smyth et al. 2011); but on the other hand when they do recognise themselves as young carers it can be against a backdrop of expectations about what normal childhood is supposed to be like, thus seeing themselves as somehow deficient (O'Dell et al. 2010). Such a conclusion is borne out by research in a Western context but other research by Skovdal and Andreouli (2011) has shown how in Kenya, there is a different recognition of childhood, in which children are seen as active agents of community life.

Research must approach the topic from within each culture's frame of reference. As such, many factors can affect the policy response including the presence of country-specific research and local championing organizations. However, where resources are scarce, particularly in so-called developing countries, simply showing that young carers are present will not lead to a response-there are insufficient resources to provide support for that specific group. There is need for discussion on what sort of services and interventions are necessary or appropriate. For example, do we need specific services that are tailor-made for young carers? Or can we use generic services to good effect? And when resources are scarce, how can they best be used to improve the lives of young carers?

One dilemma that arises from the research on young carers is whether children in countries which have no welfare benefits system should be paid for their role as carers so as to obviate their need for finding outside employment? But, if children are paid to continue to act as carers they may become locked in their caring roles and their access to schooling and education will be restricted. This limits their life chances and prevents them from achieving higher goals and better-paid employment. Such young people need appropriate support to break out of the spiral of poverty and caring, and enable them to achieve against the UN Convention on the Rights of the Child and Global Millennium Goals. Most controversially perhaps, it could also be argued that providing support for young carers in any country, rather than providing adequate care for the person they care for, also locks children into an inappropriate caring role and parents into a reliance on their children. Thus, while we think it valuable to use tools and methods that allow for cross-cultural comparisons in research findings, how these findings are interpreted and used by policy makers will not necessarily be the same. Each of our concentric circles has a different policy objective, but which of the circles is given prominence by policy makers and whether the focus is then primarily on prevention, assistance, or mitigation will depend on cultural understandings of childhood, the nature and extent of familial illness, and economic factors.

\section{Ethics of Developing the Quality of Methodology}

A broad base of evidence around the nature of caring, its prevalence and potential impacts has been established. As discussed, small scale qualitative research has been carried out with groups of young carers identifying various difficulties. Some survey research has been able to produce figures that give some indication of how widespread problems may be, but on the whole, this work has been with small and selected samples that do not permit generalization and importantly an understanding that the impacts actually arise as a result of caring. One approach to this latter issue has been to ask adults to retrospectively report on their experiences of caregiving (Lackey and Gates 2001) but while this adds weight to the observation that caring has consequences, it is methodologically limited.

Other statistical correlational research is able to show associations between variables. For example, social skills were found to be positively associated with a higher extent of caring activities (Kallander et al. 2018), but due to the cross-sectional nature of the study it is not clear if children take on caring due to their high social skills or if they develop social skills as a result of caring. Similarly, we know that many young carers experience bullying but what we don't know is whether their victimization is a result of their caring and whether the extent of their victimization exceeds that of young people who are not young carers. To find out we need prospective research and research that compares young carers with other young people.

To do this we also need new research that uses established tools that permit comparisons of findings to be made. In the past, much research has tended to use idiosyncratic measurement tools developed for single study use. However, various tools do exist, such as the Young Carers Perceived Stress Scale (Early et al. 2006), and the Multidimensional Assessment of Caring Activities (MACA-YC18: Joseph et al. 2009b). The latter tool is widely used by carers organisations 
as it yields scores for a range of caring activities, i.e., domestic activity, household management, emotional care, sibling care, personal care, and financial and practical management. This makes it useful for assessment purposes when used by social workers and health professionals. It has been increasingly used as a survey instrument across different cultures, including the United Kingdom (e.g., Becker and Sempik 2018), Sweden (e.g., Järkestig-Berggren et al. 2018), and Switzerland (e.g., Leu et al. 2019).

Increasingly researchers are in need of tools that allow comparisons to be made between young carers and their peers. As such, a revised survey version of the MACA-YC18 (Joseph et al. 2019) was developed to allow it to be used with all young people regardless of their caring role. The revised tool allows comparisons to be made between the everyday helping carried out by young people and those who are in a caring role. It is important to understand that many young people who are not in a caring role help around the home. Researchers need to understand what young carers do against the backdrop of the culturally expected and everyday level of helping by young people.

Tools to assess the effects of caring have also been developed, such as the Positive and Negative Outcomes of Caring (PANOC: Joseph et al. 2009a), which allows respondents to indicate to what extent they feel adversely affected on the one hand, and to have gained benefits, on the other. We think it is important to understand that caring can promote psychological growth for the young person. This is not to imply that we think caring is necessarily a positive event in the person's life, but recognizes that in the struggles and challenges faced by the young person, growth can ensue. As such, a focus solely on the destructive aspects of caring is unbalanced and does not provide the scope to understand fully the ways in which policy interventions can be helpful. We think that policy should not be based solely on the idea of mitigation but also on promotion of positive psychological and educational factors. In this way, evaluations should assess not only that problems and difficulties are alleviated but also that positive qualities, such as resilience, strengths, and well-being, are fostered.

We believe greater methodological rigour is needed now to advance the field in the ways described above, but for us this is an ethical issue as well as a methodological one. There is a certain degree of saturation that seems to have been reached in the qualitative literature in describing the range of difficulties and problems encountered by young people who care. As such, we would argue that sufficient work that is essentially descriptive has already been carried out and future work needs to show clearly how it could add a step change to the body of knowledge. Otherwise, we feel research becomes increasingly questionable ethically, particularly in samples that may be upset by the research (Robson 2001), and who give their time without benefit to themselves or their families. The quantitative research is at a more developmental stage, particularly in producing generalizable findings, evidence of causal relationships between variables, and prospective research that can tell us about the impact on future adult life. Larger scale studies with representative samples to determine the extent and nature of the difficulties are needed. Small scale studies with selected groups of young carers simply cannot show conclusively the extent and nature of the problems faced by young carers as one homogeneous group. And as we discussed above in our concentric circle model, young carers are not a homogeneous group. The extent and nature of the problems will likely vary according to the distinctive needs of each group. As such, while we make the same assumption ourselves that many young carers will likely experience damaged educational prospects, poorer mental health, and restricted life opportunities, and so on, questions about the extent of the difficulties faced by young carers demands larger scale quantitative evidence if they are to be taken more seriously by policy makers.

\section{More Theoretically Driven Research}

Evidence for the adverse effects of caring are limited in the ways described above, and recommendations for policy and practice currently often seem to go beyond the data, making assumptions that young carers will suffer from damaged educational prospects, poorer mental health, and restricted life opportunities. As discussed, there needs to be more rigorous quantitative work that allows for generalizability, understanding of causality, and long term effects; but alongside this there also needs to be greater theoretical sophistication.

For example, one of the pressing questions is whether caring has a statistical association with adverse outcomes. As we have seen, research findings on the relationship between the amount of caring activity and measures of well-being and mental health are mixed. However, this is not surprising as we should not expect a straightforward linear relationship between caring and other outcomes. It is known from other areas of similar research such as the stress and coping literature that such a relationship is likely to be moderated and mediated by a number of other factors. To date, research has tended to give too little attention to moderating factors. We must recognise that caring takes place in a sociological context. It is a heavily gendered activity (Aldridge 2018) and influenced by the role of ethnicity, culture, support systems across schools, communities and helping professions (Kavanaugh et al. 2016). How caring activity relates to health and wellbeing is expected to be moderated by such factors, that we might predict strong relationships between caring activity and health and well-being outcomes in some groups but not in others. 
As such, we need more theoretically driven approaches. For example, the stress process model used by Kavanaugh (2014) to take into account background factors, the primary stressors of caregiving, but also the secondary stressors such as school performance and parent/child conflict is one example of how research can be developed. Other research by Pakenham and Cox (2015) uses a family ecology framework which takes into account stress-appraisals, coping strategies, and coping resources. Their findings emphasise that higher caregiving responsibilities have direct and indirect adverse effects on youth mental health in the context of parental illness. We might also look to the literature on posttraumatic growth for inspiration on how different personality, social, and coping-related factors are likely to mediate and moderate the relationship between the experience of caring and positive outcomes (e.g., Linley and Joseph 2004).

In particular, we need to understand more about the psychological appraisal factors within the person that mediate their experience of caring. Qualitative research has identified the ways in which young people think about their caring experience, whether they see it as just part of their life, themselves as a caring person, whether they feel they have a choice, and the burden of responsibility they feel (McDonald et al. 2009). It is clear that these very idiosyncratic appraisals of what it means to be a carer, while well documented in the qualitative literature, have failed to translate into the quantitative social survey research as new variables that can help to explain the complex appraisals that young people make that mediate the relationship between their caring role and other outcomes in their life.

In this way, there is a need to apply more sophisticated theoretical frameworks that can understand that caring and its outcomes are not necessarily as straightforward as has been assumed in some past studies, but rather only understood by a closer examination of moderating and mediating factors.

\section{Young People and Those They Care for as Active Researchers}

Research with young people most often involves negotiating access through gatekeepers who will often have reasons to refuse access because of fears of a child protection intervention, invasion of privacy, or for other reasons that are deemed to actually be in the best interests of the young person or the family not to take part (Kennan et al. 2012). As such, we believe an important innovation will be for young carers researchers to step back from taking an expert frame of reference. While we think there is a need for greater sophistication in research from the researchers frame of reference, as described above, we also see opportunities for more participatory action research that engages with the young carers themselves and their families, from their frame of reference, and in their perceived best interests.

One study that offers a ground breaking example of more participatory research is that by Skovdal et al. (2009) in which young carers in Kenya used photography and drawing to provide accounts of their experiences. Their work helped to shift perspective from young carers as victims to competent social actors, and framed within a social psychology of coping. Other work of this nature has involved world café events led by young carers themselves providing insight into the here and now experiences of a group of young carers (McAndrew et al. 2012).

Participatory research with young people remains relatively rare (Raanaas et al. 2018) but finding ways in which research becomes more participatory, action-focused, and participant-led would seem to be especially responsive to what we have learned so far, in finding ways to engage more ethically with young people who care. However, as we know the time available to young carers to take part in other activities is limited, and as such their ability to participate in research will be constrained. In calling for more participatory research which is additionally demanding, we have an ethical duty to young people to provide sufficient resources so as not to add to their burden. Participatory research can be especially appealing to policy makers, more visible to the public creating awareness, and may also be helpful to the development and experience of the young carers themselves. We would encourage researchers and service providers to think about how a participatory research element can be built into existing and new plans.

\section{Multi-agency and Interdisciplinary Focus}

It has been argued that the concept of a young carer distracts from inadequate state services and legitimizes abuse of children, and as such, the focus should be on helping parents fulfil their roles, not in supporting children and young people to be carers (Morris 1997). As discussed above, we agree that it is important that the research into young carers is not misused in this way and that full attention must be given to supporting parents, and other adults with illness or disability, as a first priority of policy. But research into the experiences of young people themselves shows that it is not helpful to see this issue dichotomously and that even if parents are fully supported those identified as young carers would continue to have their own needs for support (Thomas et al. 2003). Prevention, assistance, and mitigation/promotion require a range of disciplines and professionals to be involved, i.e., educators, healthcare professionals, community workers, and social workers, all of whom bring different skills and expertise (Warren 2007). When not viewed in this dichotomous way, it is clear that the field demands a multi-disciplinary and multi-agency approach. 
A study conducted in Germany (Kaiser and Schulze 2014,2015 ) showed that professionals working in education, health or social care only regarded support provided by inter-agency cooperation to be effective for children and adolescents who had caring responsibilities and who had problems with school attendance. However, issues of professional confidentiality and the private (and hence invisible) nature of children's caring roles undermined inter-agency working and support. Social workers have a central role as they are the most likely to be working with families of ill and disabled people. Educators and teachers must also be involved as they are in direct daily contact with young people. Within school contexts, ensuring that confidential guidance and counselling is available may be helpful given the often covert nature of caring which may prohibit the use of other services (Banks et al. 2002).

The recognition of the need for a multi-agency approach is mirrored in the need for interdisciplinary research. Each scholarly discipline brings with it its own set of assumptions and positionality. For example, sociologists may conduct research which emphasises the gendered nature of caring and the role of public policy in providing solutions to what are seen as culturally created problems. Psychologists may approach the topic from the perspective of the individual studying, for example, processes of coping and resilience, with suggestions for how clinical or counselling psychologists can be more involved.

But the topic of young caring crosses disciplines of sociology, psychology, as well as education, public policy, social work, law, medical ethics and others, and thus demands greater interdisciplinary working and awareness. For example, interest in resilience and coping may be a helpful line of investigation, but only if it is not at the expense of helping parents fulfil their roles. What we are suggesting is that truly interdisciplinary research is able to offer the bird's eye view on any research and how its significance is positioned within the larger field. Related to this is that the professional groups traditionally involved with young carers tend to adopt an approach grounded in an illness ideology, so policy and practice can become overly driven by a focus on the pathological. While there is a role for this, research also stresses the personal growth, maturity, and identity formation processes pointing to the development of positive psychological and positive educational interventions, which we believe need to become more prominent as we move away in our thinking from an illness ideology that pathologizes young people who care. We need to do more than help young people cope, deal with the stress, and so on; we need to help them flourish.

\section{Conclusion}

We aimed to provide a critical discussion of the issues and challenges facing young carers researchers in the coming years and to provide directions for how the field now moves forward. First, we proposed a new concentric circles conceptualization of caring that recognises that the policy targets for all young people will not be the same. A broad definition of caring must inevitably be at the heart of public policy if it is to help address the complex web of the different needs of families to reduce the burden of care, support young people who care, and address the problems that arise from caring. But a broad definition covers caring in all its forms as if these young people belong to one single population. There are different groups of carers within this wider population. Second, each of the groups represented by our concentric circles will have a different policy objective, but which of the circles is given prominence by policy makers and whether the focus is then primarily on prevention, assistance, or mitigation will depend on cultural understandings of childhood, and social and economic factors in each country. Third, there is already much research of a small scale and descriptive nature that we would now question the ethics of further research which does not offer advances that build on this previous research. There is a need for greater methodological sophistication in research to produce results that are generalizable, able to show the causal relationships of variables, and the longer term prospective impacts. Fourth, more theoretically-driven research is needed. It is clear that not all young people who care have difficulties in health, well-being or education; for some it is likely that the experience of caring is beneficial to them and leads to a maturity and competence in the world that serves them well. To date, the picture painted has been a simplistic one that caring is necessarily harmful. It is not, but it can be, and we now need to understand the mediators and moderators that influence the relationship between caring and these outcomes. Fifth, we see a real problem if there is only research from the researchers' frame of reference and call for participatory and action led research that can provide greater insights into the lived experiences of young people, their needs and how these can be met. Finally, such research must come from all disciplinary corners so that we do not lose sight of the social and cultural process at the expense of psychologizing young caring with concepts of coping and resilience, and vice versa, we must not lose sight of the psychological. All disciplines have their approach, and research from any disciplinary corner has inbuilt assumptions for policy and practice, which we now recognise has to be multiagency involving schools, universities, health services, social services and professionals from education, psychology, and social work. 
Open Access This article is distributed under the terms of the Creative Commons Attribution 4.0 International License (http://creativeco mmons.org/licenses/by/4.0/), which permits unrestricted use, distribution, and reproduction in any medium, provided you give appropriate credit to the original author(s) and the source, provide a link to the Creative Commons license, and indicate if changes were made.

\section{References}

Aldridge, J. (2018). Where are we now? Twenty-five years of research, policy and practice on young carers. Critical Social Policy, 38(1), $155-165$.

Aldridge, J., \& Becker, S. (1993). Children who care: Inside the world of young carers. Loughborough, UK: Loughborough University, Young Carers Research Group.

Banks, P., Cogan, N., Riddell, S., Deeley, S., Hill, M., \& Tisdall, K. (2002). Does the covert nature of caring prohibit the development of effective services for young carers? British Journal of Guidance and Counselling, 30(3), 229-246.

Barry, M. (2011). 'I realised that I wasn't alone': The views and experiences of young carers from a social capital perspective. Journal of Youth Studies, 14(5), 523-539.

Becker, S. (2000). Young carers. In M. Davies (Ed.), The Blackwell encyclopaedia of social work (p. 378). Oxford: Blackwell.

Becker, S. (2007). Global perspectives on children's unpaid caregiving in the family: Research and policy on 'Young Carers' in the UK, Australia, the USA, and Sub-Saharan Africa. Global Social Policy, 7(1), 23-50.

Becker, F., \& Becker, S. (2008). Young adult carers in the UK. Experiences, needs and services for carers aged 16-24. London: The Princess Royal Trust for Carers.

Becker, S., \& Sempik, J. (2018). Young adult carers: The impact of caring on health and education. Children and Society. https://doi. org/10.1111/chso. 12310 .

Bjorgvinsdottir, K., \& Halldorsdottir, S. (2013). Silent, invisible and unacknowledged: Experiences of young caregivers of single parents diagnosed with multiple sclerosis. Scandinavian Journal of Caring Science, 28(1), 38-48.

Bolas, H., Wersch, A. V., \& Flynn, D. (2007). The well-being of young people who care for a dependent relative: An interpretative phenomenological analysis. Psychology and Health, 22(7), 829-850.

Cluver, L., Operario, D., Lane, T., \& Kganakga, M. (2012). "I Can’t Go to School and Leave Her in So Much Pain" Educational shortfalls among adolescent 'Young Carers' in the South African AIDS epidemic. Journal of Adolescent Research, 27(5), 581-605.

Cluver, L., Orkin, M., Moshabela, M., Kuo, C., \& Boyes, M. (2013). The hidden harm of home-based care: Pulmonary tuberculosis symptoms among children providing home medical care to HIV/ AIDS-affected adults in South Africa. AIDS Care, 25(6), 748-755.

Cree, V. E. (2003). Worries and problems of young carers: Issues for mental health. Child and Family Social Work, 8, 301-309.

Early, L., Cushway, D., \& Cassidy, T. (2006). Perceived stress in young carers: Development of a measure. Journal of Child and Family Studies, 15(2), 165-176.

Evans, R., \& Becker, S. (2009). Children caring for parents with HIV and AIDS. Bristol: Policy Press.

Fives, A., Kennan, D., Canavan, J., \& Brady, B. (2013). Why we still need the term 'Young Carer': Findings from an exploratory study of young carers in Ireland. Critical Social Work, 14(1), 49-61.

Gray, B., Robinson, C., \& Seddon, D. (2008). Invisible children: Young carers of parents with mental health problems-the perspectives of professionals. Child and Adolescent Mental Health, 13(4), 169-172.
Hamilton, M. G., \& Adamson, E. (2013). Bounded agency in young carers' lifecourse-stage domains and transitions. Journal of Youth Studies, 16(1), 101-117.

Health Services Act. (2010). Hälso- och sjukvårdslag (1982:763), Socialdepartementet, Utfärdad: 1982-06-30, Omtryck: SFS 1992:567, Ändring införd: tom SFS 2016:1298. Retrieved 7/1/2017. http://rkrattsbaser.gov.se/sfst?bet=1982:763).

Hill, T., Smyth, C., Thomson, C., \& Cass, B. (2009). Young carers: Their characteristics and geographical distribution. Canberra, Australia: Social Policy Research Centre.

Hunt, G., Levine, C., \& Naiditch, L. (2005). Young caregivers in the US: Findings from a national survey. Bethesda, MD: National Alliance for Care Giving and the United Hospital Fund.

Järkestig-Berggren, U., Bergman, A. S., Eriksson, M., \& Priebe, G. (2018). Young carers in Sweden: A pilot study of care activities, view of caring, and psychological well-being. Child and Family Social Work. https://doi.org/10.1111/cfs.12614.

Joseph, S., Becker, S., \& Becker, F. (2009a). Manual for measures of caring activities and outcomes for children and young people. London: The Princess Royal Trust for Carers.

Joseph, S., Becker, S., Becker, F., \& Regel, S. (2009b). Assessment of caring and its effects in young people: Development of the Multidimensional Assessment of Caring Activities Checklist (MACA-YC18) and the Positive and Negative Outcomes of Caring Questionnaire (PANOC-YC20) for young carers. Child: Care, Health and Development, 35, 510-520.

Joseph, S., Kendall, C., Toher, D., Sempik, J., Holland, J., \& Becker, S. (2019). Young carers in England: Findings from the 2018 BBC survey on the prevalence and nature of caring among young people. Child: Care, Health and Development. First online publication.

Joseph, S., Mynard, H., \& Mayall, M. (2000). Life-events and posttraumatic stress in a sample of English adolescents. Journal of Community \& Applied Social Psychology, 10(6), 475-482.

Kaiser, S., \& Schulze, G. C. (2014). Pflegerische Tätigkeiten in der Familie-eine mögliche Ursache für Schulabsentismus bei Kindern und Jugendlichen. Zeitschrift für Heilpädagogik, 9, 332-346.

Kaiser, S., \& Schulze, G. C. (2015). Between inclusion and participation: Young carers who are absent from school. Journal of Cognitive Education and Psychology, 14(3), 314-328.

Kallander, E. K., Weimand, B. M., Becker, S., Van Roy, B., HanssenBauer, K., Stavnes, K., et al. (2018). Children with ill parents: Extent and nature of caring activities. Scandinavian Journal of Caring Sciences, 32(2), 793-804.

Kavanaugh, M. S. (2014). Children and adolescents providing care to a parent with Huntington's disease: Disease symptoms, caregiving tasks and young carer well-being. Child \& Youth Care Forum, 43(6), 675-690.

Kavanaugh, M. S., Stamatopoulos, V., Cohen, D., \& Zhang, L. (2016). Unacknowledged caregivers: A scoping review of research on caregiving youth in the United States. Adolescent Research Review, 1(1), 29-49.

Kennan, D., Fives, A., \& Canavan, J. (2012). Accessing a hard to reach population: Reflections on research with young carers in Ireland. Child and Family Social Work, 17(3), 275-283.

Kettell, L. (2018). Young adult carers in higher education: The motivations, barriers and challenges involved-a UK study. Journal of Further and Higher Education. https://doi.org/10.1080/03098 77X.2018.1515427.

Lackey, N. R., \& Gates, M. F. (2001). Adults' recollections of their experiences as young caregivers of family members with chronic physical illnesses. Journal of Advanced Nursing, 34(3), 320-328.

Leu, A., \& Becker, S. (2017a). A cross-national and comparative classification of in-country awareness and policy responses to 'young carers'. Journal of Youth Studies, 20(6), 750-762. https://doi. org/10.1080/13676261.2016.1260698. 
Leu, A., \& Becker, S. (2017b). Länderspezifisches Bewusstsein zur Situation von Young Carers: Eine globale Betrachtung. In ZQP Zentrum für Qualität in der Pflege (Ed.), Kinder und Jugendliche als pflegende Angehörige. ZQP-Themenreport. Berlin.

Leu, A., \& Becker, S. (2019). Young Carers. In H. Montgomery (Ed.), Oxford bibliographies in childhood studies. New York: Oxford University Press.

Leu, A., Frech, M., Wepf, H., Sempik, J., Joseph, S., Helbling, L., et al. (2019). Counting young carers in Switzerland: A study of prevalence. Children and Society, 33(1), 53-67. https://doi.org/10.1111/ chso.12296.

Leu, A., Jung, C., \& Frech, M. (2016a). Erwachsene, Jugendliche und junge Erwachsene als pflegende Angehörige in der Schweiz. Paediatrica, 27, 1-3.

Leu, A., Jung, C., \& Frech, M. (2016b). Kinder und Jugendliche sind besonders schutzbedürftig: Kinder, Jugendliche und junge Erwachsene als pflegende Angehörige in der Schweiz. Clinicum, 4, 39-41.

Linley, P. A., \& Joseph, S. (2004). Positive change following trauma and adversity: A review. Journal of Traumatic Stress, 17(1), $11-21$.

Lloyd, K. (2013). Happiness and well-being of young carers: Extent, nature and correlates of caring among 10 and 11 year old school children. Journal of Happiness Studies, 14(1), 67-80.

McAndrew, S., Warne, T., Fallon, D., \& Moran, P. (2012). Young, gifted, and caring: A project narrative of young carers, their mental health, and getting them involved in education, research and practice. International Journal of Mental Health Nursing, 21(1), 12-19.

McDonald, J., Cumming, J., \& Dew, K. (2009). An exploratory study of young carers and their families in New Zealand. Kōtuitui: New Zealand Journal of Social Sciences Online, 4(2), 115-129.

Metzing-Blau, S., \& Schnepp, W. (2008). Young carers in Germany: To live on as normal as possible: A grounded theory study. BMC Nursing, 7(1), 15.

Moore, T., \& McArthur, M. (2007). We're all in it together: Supporting young carers and their families in Australia. Health and Social Care in the Community, 15(6), 561-568.

Moore, T., McArthur, M., \& Morrow, R. (2009). Attendance, achievement and participation: Young carers' experiences of school in Australia. Australian Journal of Education, 53(1), 5-18.

Moore, T., Morrow, R., McArthur, M., Noble-Carr, D., \& Gray, J. (2006). Reading, wrting and responsibility: Young carers and education. Dickson: ACU National for the ACT Department of Disability, Housing and Community Services.

Morris, J. (1997). A response to Aldridge and Becker: 'Disability rights and the denial of young carers: The dangers of zero-sum arguments'. Critical Social Policy, 17, 133-135.

Nagl-Cupal, M., Daniel, M., Kainbacher, M., Koller, M., \& Mayer, H. (2015). Kinder und Jugendliche als pflegende Angehörige: Einblick in die Situation Betroffener und Möglichkeiten der Unterstüzung. T. 1, Einsicht in die Situation gegenwärtiger und ehemaliger pflegender Kinder in Österreich (Vol. 19, p. 265). ÖGB-Verl.

Nagl-Cupal, M., Daniel, M., Koller, M. M., \& Mayer, H. (2014). Prevalence and effects of caregiving on children. Journal of Advanced Nursing, 70(10), 2314-2325.

Newman, T. (2002). 'Young carers' and disabled parents: Time for a change of direction? Disability \& Society, 17(6), 613-625.

O’Dell, L., Crafter, S., de Abreu, G., \& Cline, T. (2010). Constructing 'normal childhoods': Young people talk about young carers. Disability \& Society, 25(6), 643-655.

Olsen, R. (1996). Young carers: Challenging the facts and politics of research into children and caring. Disability \& Society, 11(1), 41-54.

Olsen, R. (2000). Families under the Microscope: Parallels between the Young Carers Debate of the 1990s and the Transformation of Childhood in the Late Nineteenth Century. Children and Society, 14(5), 384-394.
Pakenham, K. I., \& Cox, S. (2015). The effects of parental illness and other ill family members on youth caregiving experiences. Psychology \& Health, 30(7), 857-878.

Purcal, C., Hamilton, M., Thomson, C., \& Cass, B. (2012). From assistance to prevention: Categorizing young carer support services in Australia, and international implications. Social Policy \& Administration, 46(7), 788-806.

Raanaas, R. K., Bjøntegaard, H. Ø., \& Shaw, L. (2018). Adolescent Research Review. https://doi.org/10.1007/s40894-018-0097-0.

Robson, E. (2001). Interviews worth the tears? Exploring dilemmas of research with young carers in Zimbabwe. Ethics, Place \& Environment, 4(2), 135-142.

Robson, E. (2004). Hidden child workers: Young carers in Zimbabwe. Antipode, 36(2), 227-248.

Robson, E., Ansell, N., Huber, U. S., Gould, W. T. S., \& van Blerk, L. (2006). Young caregivers in the context of the HIV/AIDS pandemic in Sub-Saharan Africa. Population, Space and Place, 12(2006), 93-111.

Rose, H. D., \& Cohen, K. (2010). The experiences of young carers: A meta-synthesis of qualitative findings. Journal of Youth Studies, 13(4), 473-487.

Sempik, J., \& Becker, S. (2013). Young adult carers at school: Experiences and perceptions of caring and education. London: Carers Trust.

Sempik, J., \& Becker, S. (2014a). Young adult carers at College and University. London: Carers Trust.

Sempik, J., \& Becker, S. (2014b). Young adult carers and employment. London: Carers Trust.

Skovdal, M., \& Andreouli, E. (2011). Using identity and recognition as a framework to understand and promote the resilience of caregiving children in western Kenya. Journal of Social Policy, 40(3), 613-630.

Skovdal, M., Ogutu, V. O., Aoro, C., \& Campbell, C. (2009). Young carers as social actors: Coping strategies of children caring for ailing or ageing guardians in Western Kenya. Social Science and Medicine, 69(4), 587-595.

Smyth, C., Blaxland, M., \& Cass, B. (2011). 'So that's how I found out I was a young carer and that I actually had been a carer most of my life' Identifying and supporting hidden young carers. Journal of Youth Studies, 14(2), 145-160.

Stamatopoulos, V. (2015). One million and counting: The hidden army of young carers in Canada. Journal of Youth Studies, 18(6), 809-822.

Stamatopoulos, V. (2016). Supporting young carers: A qualitative review of young carer services in Canada. International Journal of Adolescence and Youth, 21(2), 178-194.

Stamatopoulos, V. (2018). The young carer penalty: Exploring the costs of caregiving among a sample of Canadian youth. Child \& Youth Services, 39(2-3), 180-205.

Svanberg, E., Stott, J., \& Spector, A. (2010). 'Just helping': Children living with a parent with young onset dementia. Aging \& Mental Health, 14(6), 740-751.

Thomas, N., Stainton, T., Jackson, S., Cheung, W. Y., Doubtfire, S., $\&$ Webb, A. (2003). Your friends don't understand': Invisibility and unmet need in the lives of 'young carers. Child and Family Social Work, 8(1), 35-46.

Warren, J. (2007). Young carers: Conventional or exaggerated levels of domestic and caring tasks. Children and Society, 21(2), 136-146.

Wayman, S., Raws, P., \& Leadbitter, H. (2016). There's nobody is there-no one who can actually help? The challenges of estimating the number of young carers and knowing how to meet their needs. London: Children's Society.

Publisher's Note Springer Nature remains neutral with regard to jurisdictional claims in published maps and institutional affiliations. 